Research Article

\title{
Numerical Study on the Entrance Effect of Penetration into Concrete Targets
}

\author{
Huawei Yang $\mathbb{D}^{1}{ }^{1}$ Ji-wei Luo $\mathbb{D},{ }^{1}$ Jie Zhang, ${ }^{2,3}$ and Pei-wen Zhang $\mathbb{D}^{1}$ \\ ${ }^{1}$ College of Management Science and Engineering, Shanxi University of Finance and Economics, Taiyuan 030006, China \\ ${ }^{2}$ Shanxi Key Lab. of Material Strength \& Structural Impact, Taiyuan 030024, Shanxi, China \\ ${ }^{3}$ Institute of Applied Mechanics, Taiyuan University of Technology, Taiyuan 030024, Shanxi, China \\ Correspondence should be addressed to Pei-wen Zhang; zhangpw@sxufe.edu.cn
}

Received 15 March 2021; Revised 4 November 2021; Accepted 9 November 2021; Published 9 December 2021

Academic Editor: Nouman Ali

Copyright $\odot 2021$ Huawei Yang et al. This is an open access article distributed under the Creative Commons Attribution License, which permits unrestricted use, distribution, and reproduction in any medium, provided the original work is properly cited.

\begin{abstract}
Investigation on penetration into concrete targets is of great importance as concrete is widely used as the fundamental construction material. To achieve a more accurate prediction of penetration depths of concrete targets, a further study was conducted to explore the entrance effect by using AUTODYN hydrocode in this study. The numerical results on both deceleration-time history and depth of penetration of projectiles are in good agreement with experimental data, which demonstrate the feasibility of the numerical model in these conditions. A new target model was established with a predrilled hole around the symmetry axis to simulate the entrance effect of the crater phase on the penetration process. Compared with the regular target, the predrilled target enters the peak of acceleration earlier, leading to the reduction of the depth of penetration. In addition, simulation results indicated that nose shape significantly influenced crater region depth, while the depth was independent of the impact velocity and the target strength. Based on the simulation of entrance effect, a modified formula of penetration depth has been proposed and validated in terms of different nose shapes. The crater region depths obtained from the simulations can improve the accuracy of the predictions of the penetration depths for the penetration of concrete targets.
\end{abstract}

\section{Introduction}

In view of the protection mechanism of materials and structures under dynamic impact, such as precision strikes, explosion, and earthquake, the dynamic behaviours of metallic materials and nonmetallic materials such as steel $[1]$, soil $[2,3]$, concrete $[4,5]$, and cellular structures [6-8] have been studied systematically in terms of experiment with SHPB or explosion tests, numerical simulations with LSDYNA, AUTODYN, and theoretical analysis based on dynamic constitutive relation. As for concrete, it has played an important role in constructions for a long time. It is of great importance to study the anti-impact performance of concrete within the perspective of protective engineering. To make a more accurate prediction of penetration depths of concrete targets is of great importance in the underground defensive project. Penetration is a process with large strain, high strain rate, and high pressure, in which the dynamic responses of both the projectile and target are very complicated [9], especially for concrete targets that exhibit complicated nonlinear behavior under dynamic loadings [10]. In addition, the effects of strain rate and crack propagation on the mechanical properties of concrete have not been clearly described due to its brittle properties, which play important roles in the penetration process. Thus, it is difficult to make accurate predictions of the penetration process for concrete targets.

In the past decades, sets of experiments have been performed to investigate the penetration into concrete targets by different projectiles, and a number of empirical formulations have been developed to describe the experimental phenomena and results. Most of these formulations are unit dependent that complicate the comparison of different experimental results. The recent progress in the formulation and modelling of local impact effects in concrete targets penetrated by hard missiles was summarized in detail $[11,12]$. In subsequent works, modified and simplified formula equations based on the previous work were 
proposed and validated $[13,14]$. Obviously, the formulations are consistent with the experimental data. However, each empirical formulation has an individual application range in terms of mass, velocity, material strength, the geometry size of projectiles, and the mechanical properties of the concrete targets.

The penetration process for thick concrete targets has two main stages: initial crater and hole enlargement. A conical region is first formed when a projectile impacts a target; as the projectile penetrates into the target further, the penetration enters the hole enlargement stage. Then, a cylinder tunnel region is formed in the target. The entrance phase for a concrete target significantly affects the entire penetration or perforation process. In a classic work [15], the force required to push a conical-nosed steel rod into a thick copper plate was measured and the force stabilised only after the rod reached a depth of approximately 4-5 rod diameters. On the basis of these work, an empirical equation was developed for the penetration depth of concrete targets with the assumption that crater region depth is twice the projectile diameter [16-18]. This penetration equation has been extensively used to predict the penetration depth for a concrete target penetrated by a nondeformable projectile at normal velocity. Based on those works, a new equation to define crater region depth for penetration depth prediction was proposed and the results are encouraging [19]. Up to now, the quantitative description of the crater depth is still not accurate enough.

Although the entrance phase plays an important role in the penetration process, few studies have been focused on it. Thus, detailed investigation on the entrance effect is quite necessary. In addition, the model of a target with a predrilled hole can be modified to investigate the entrance effect and crater depth. In this paper, a modified formula was proposed to make a more accurate prediction of penetration depths of concrete targets, based on the numerical simulation of entrance effect using AUTODYN-2D. In Section 2, Forrestal's formula proposed in Ref. [16-18] was introduced in detail. The numerical method was introduced and validated in Section 3. In Section 4, the entrance effect on the penetration depth was discussed in detail, a modified formula was proposed and validated.

\section{Formulas of Penetration Depth Prediction}

Much experimental phenomena involving the impaction of soil and concrete targets by ogive-nosed projectiles show that the penetration cavity consists of a conical region with a length that comprises approximately two projectile shank diameters $2 d$, followed by a circular cylinder with a diameter that is almost equal to projectile shank diameter, $d$. Hence, the conical region and the circular cylinder are called the crater and tunnel regions, respectively. These two penetration regions are depicted in Figure 1(a). The total penetration depth is equal to the sum of crater region depth and tunnel region depth. To highlight the strong effect of the entrance phase on the penetration process further, simulations are conducted on concrete targets that display a cylindrical hole around the symmetry axis from the front surface. This hole can prevent the target surfaces from moving as a result of the projectile inside. The holes have a diameter of $80 \mathrm{~mm}$, which is only slightly larger than the projectile diameter, and a depth of $H=532 \mathrm{~mm}$, which is identical to the length of the projectile and is deep enough to offset the effect of the free impact surface by moving the impact area deep into the target. Hence, the entrance phase hardly affects penetration. The numerical models are depicted in Figure 1(b). In the simulations, the Johnson Cook model was employed to develop the projectile. Projectile geometry is demonstrated in Figure 1(d)

2.1. Forrestal's Formula of Penetration Depth. On the basis of cavity-expansion analyses, an empirical equation to predict the penetration depth of concrete targets was proposed [9]. In this model, the retarding stress on the projectile nose is expressed as

$$
\begin{aligned}
& F=c z, \quad 0<z<2 d, \\
& F=\frac{\pi d^{2}}{4}\left(R+N \rho V^{2}\right), \quad z>2 d,
\end{aligned}
$$

where $c$ is a constant; $z$ is measured on the target front surface along impact direction; $R$ is the strength terms (static resistance), which has considered the size effect; $V$ is the realtime impact velocity; and $p=f(v / \alpha, e)$ is the density of the concrete targets. The calibre-radius-head $(\mathrm{CRH})$ is determined with $\Psi=R / d$. $N$ is a key parameter depending on the nose shape and is defined as follows for ogive-nosed projectiles:

$$
N=\frac{8 \psi-1}{24 \psi^{2}}
$$

$P$ and $a$ are the final penetration depth and deceleration and can be calculated as follows:

$$
\begin{aligned}
& P=\frac{2 m}{\pi d^{2} \rho N} \ln \left(1+\frac{N \rho V_{1}^{2}}{R}\right)+2 d, \\
& a=\frac{-\left[\pi d^{2} R /(4 m)\right]}{\cos ^{2}\left\{\tan ^{-1}\left[(N \rho / R)^{1 / 2} V\right]_{1}-\pi d^{2} / 4 m(R N \rho)^{1 / 2}\left(t-t_{1}\right)\right\}},
\end{aligned}
$$

where $m$ is the mass of the projectile and $t_{1}$ and $V_{1}$ are defined as the time and projectile velocity at $z=2 d$, respectively. The corresponding equations take the following forms: 


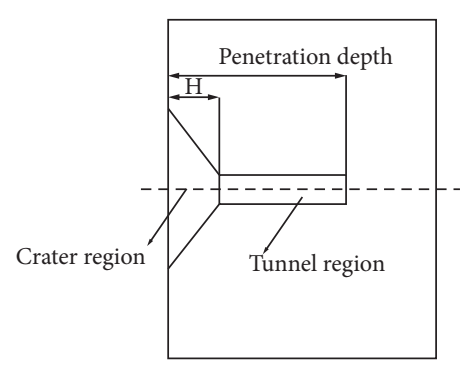

(a)
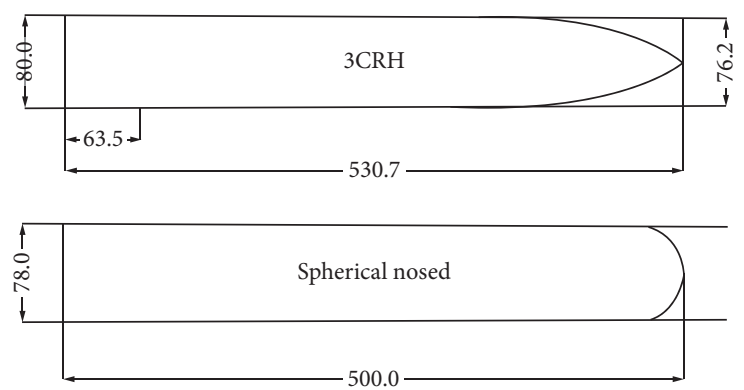

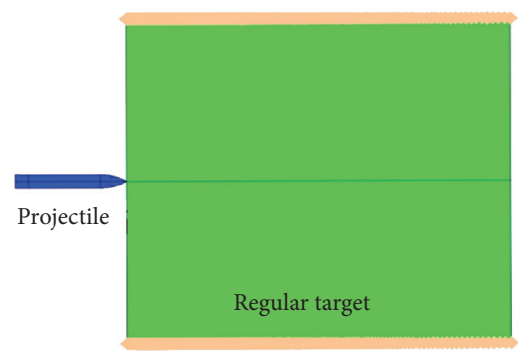

(b)

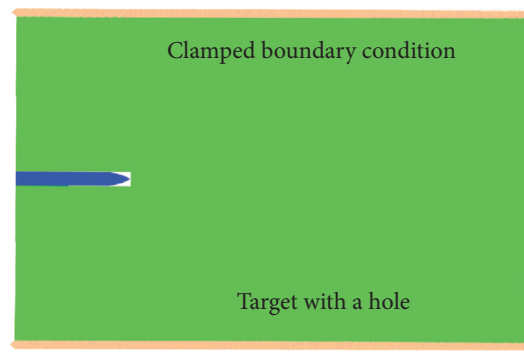

(c)
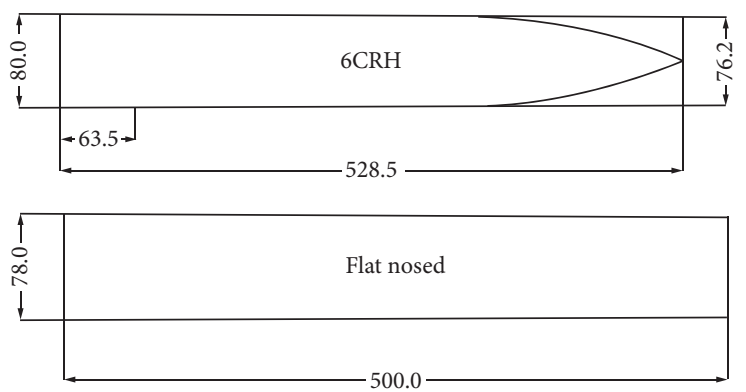

(d)

Figure 1: Penetration model: (a) crater and tunnel region of the concrete targets after penetration, (b) regular target, (c) target with a predrilled hole, and (d) projectiles with different nose shapes.

$$
\begin{aligned}
R & =\frac{N \rho V_{s}^{2}}{\left(1+\left(\pi d^{3} N \rho / 2 m\right)\right) \exp \left[\pi d^{2}(P-2 d) N \rho / 2 m\right]-1}, \\
c & =\frac{\pi d}{2}\left(R+N V_{1}^{2} \rho\right), \\
V_{1}^{2} & =\frac{2 m V_{s}^{2}-\pi d^{3} R}{2 m+\pi d^{3} N \rho} .
\end{aligned}
$$

\section{Numerical Simulations and Validation}

3.1. Finite Element Model. In the present study, one group of the experiments in [9] is referenced for the simulations. The $23 \mathrm{MPa}$ cylindrical concrete target with a standard deviation of $2.4 \mathrm{MPa}$ had a diameter and length of $1.83 \mathrm{~m}$. Ogive-nosed projectiles with $\mathrm{CRH}=3$ were machined from 4340 Rc45 steel. Geometries of the projectiles used in the simulations were demonstrated in Figure $1(\mathrm{~d})$. The geometry of the concrete target keeps the same with experiments. In consideration of the symmetry of the penetration model, only one half of the model was established in AUTODYN-2D [20]. A clamped boundary condition was implemented on the concrete target since the targets were cast in corrugated steel culverts in the experiments, as illustrated in Figure 1(b). The impact regions of the cylindrical concrete targets were modelled with $6-\mathrm{mm}$ grids, and the slightly deformed regions were meshed with a larger grid. By contrast, the projectiles were meshed with 6-mm grids. Mesh sensitivity studies revealed that further refinement does not significantly improve calculation accuracy.
Contact, sliding, and separation between the projectile and the concrete target are simulated according to gap interaction logic. By this logic, each surface segment is surrounded by a contact detection zone, the radius of which is called the gap size. Any node entering the contact detection zone of a surface segment is repelled by a force that is proportional to the penetration depth of the node into the contact detection zone [21]. In addition, the projectile and target were separated prior to calculation to facilitate gap size validation and to ensure that all the parts involved in the interactions were separated in accordance with the gap size (set at $0.32 \mathrm{~mm}$ in this model). An erosion criterion based on $200 \%$ geometric strain was followed for the concrete target [13]. It should be pointed out that sliding friction is not taken into consideration as the influence is so little that can be neglected.

\subsection{Material Properties}

3.2.1. Material Model of Projectiles. The projectiles used in the experiments were machined from 4340Rc45 steel. These projectiles did not undergo significant deformation and erosion in the penetration process because the striking velocity is within the range of $130-460 \mathrm{~m} / \mathrm{s}$. In the simulations, the material of the projectile was set as the Johnson Cook model, and the property parameters are presented in Table 1.

3.2.2. Material Model of Concrete. The RHT(Riedel-Hiermaier-Thoma) model was developed to enhance the $\mathrm{JH}$ (Johnson-Holmquist) concrete model by introducing several new features. This action has been implemented in 
TABle 1: Parameters of 4340 steel.

\begin{tabular}{lccc}
\hline Density $\left(\mathrm{g} / \mathrm{cm}^{3}\right)$ & Bulk modulus $(\mathrm{MPa})$ & Shear modulus $(\mathrm{MPa})$ & Yield stress $(\mathrm{MPa})$ \\
\hline 7.83 & $1.59 E+05$ & $7.7 E+04$ & $7.92 E+02$ \\
\hline
\end{tabular}

AUTODYN [12]. In the simulations, the concrete targets were defined by the $F=c z, \quad 0<z<2 d$ EOS, RHT strength model, and RHT failure model. The parameters of the $35 \mathrm{MPa}$ concrete material were detailed in the Standard Material Library of AUTODYN. The main material parameter for the $23 \mathrm{MPa}$ concrete was chosen from the AUTODYN material library (35 MPa concrete), whereas the secondary parameters were modified according to the experimental data, as listed in Table 2.

3.3. Validation of the Numerical Method. To enhance the reliability of the simulation results, three sets of simulations are performed with different initial impact velocities: 200, 336.6 , and $378.6 \mathrm{~m} / \mathrm{s}$. The penetration models are displayed in Figure 1(b). Figures 2(a)-2(c) exhibits the deceleration process of the simulations, compared with the results of experiments. The deceleration-time histories were recorded with an on-board single-channel acceleration data recorder in Ref. [17]. As shown in Figures 2(a)-2(c), numerical results of deceleration-time history are compared with corresponding experimental results, and reasonably good agreements were observed. It demonstrates the effectiveness of the numerical model within the velocity range tested in Ref. [17].

The experimental penetration depth $P$, calculated penetration depth $P_{c}$, and simulated penetration depth $P_{s}$ are presented in Table 3 . The simulated penetration depths are very close to the experimental data and calculated penetration depths. For the three different initial velocities, the simulated penetration depths are $12.6 \%$ higher, $2.9 \%$ higher, and $2.5 \%$ lower than the experimental penetration depths, respectively; while they are $13.7 \%$ higher, $3.9 \%$ lower, and $5.7 \%$ lower than the calculated penetration depths obtained from the semi-empirical model, respectively. The errors are completely within the acceptable range. Thus, this penetration model is effective for penetration depth prediction.

\section{Results and Discussion}

This section presents and discusses the simulation results for the entrance phase effect (Section 4.1) and crater region depths (Section 4.2). Furthermore, a modified empirical formula is proposed based on the simulation results and validated (Section 4.3).

\subsection{Penetration Process and Entrance Effect}

4.1.1. Penetration of Regular Targets. Figures 3(a) and 3(b) shows the penetration depth and velocity histories of the ogive-nosed $3 \mathrm{CRH}$ projectiles at three different impact velocities, respectively. As shown in Figure 3(a), the penetration depths of the projectiles exhibit a decreasing trend, which is called a "spring-back effect"; therefore, the projectile accelerates in the opposite direction once the initial speed drops to zero. This trend can also be observed in the velocity-time histories. Figure 3(b) clearly indicates that the three curves are linear and parallel to one another, which means that the acceleration values and the axial forces on the projectile are approximately equal. As discussed in the previous section, the resistive force on the projectile exerted by the target can be expressed through equation (2), $F=\left(\pi d^{2} / 4\right)\left(R+N \rho V^{2}\right)$. The values are equal; therefore, strength terms $R$ (static resistance) are equal. Unlike this term, the value of inertial term $N \rho V^{2}$ is low enough to be neglected at low impact velocity. Hence, velocity has little influence on the axial force exerted on the nose at low impact velocity. However, inertial term $N \rho V^{2}$ contributes more to deceleration and cannot be neglected at a high velocity, since the value of this term increases sharply with the increase of impact velocity.

As displayed in Figures 2(a)-2(c), many small local peaks are detected in all the deceleration-time histories presented in this work. These periodic peaks are the result of the stress wave reverberations along the projectile, and the time period is determined according to the length of the rod and its elastic wave speed. A close analysis suggests that variation in simulated deceleration is considerably more significant than in the experimental results. The deceleration-time curve is adequately accurate to reflect the downtrend in the acceleration, which increases rapidly after the projectile impacts the target surface before reaching a stable phase. Furthermore, the increasing phase is shortened at high impact velocities. The increase in deceleration is attributed to the immersion process of the ogive nose in the target, and the resisting force on the projectile increases until its nose is fully embedded. In addition, the stable phases of penetration are shorter in the simulations than in the experiments.

Figure 4 shows the distribution of pressure field over projectile surface in the penetration process for concrete target penetrated by a $3 \mathrm{CRH}$ projectile at $337.6 \mathrm{~m} / \mathrm{s}$. It is clearly seen that a crater region was first deformed and then a tunnel region followed. Figure 5 illustrates the final damage patterns of the different concrete targets to highlight the characteristics of the impact crater on the front face of the target. The three targets are penetrated by a $3 \mathrm{CRH}$ projectile at $337.6 \mathrm{~m} / \mathrm{s}$. It is observed that concrete target modelled with RHT behaves more or less like a constitutive model for metals (ductile materials), and the damage mode of the concrete target is far from consistent with the experimental observations. These observations were also found in the numerical simulations with RHT model [21-24]. This is not only caused by the characteristics of the RHT model but also caused by the limitations of the commercial hydrocode AUTODYN. This limitation implies that the RHT model cannot describe the damage modes of concrete target very well in its present form, especially for impact cratering or 
TABle 2: Critical parameters for $23 \mathrm{MPa}$ concrete of RHT model [12].

\begin{tabular}{lc}
\hline Parameter & Value \\
\hline Ref. Density $(\mathrm{kg} / \mathrm{cm} 3)$ & $2.75 E-03$ \\
EOS & \\
$\rho_{\text {porous }}\left(\mathrm{kg} / \mathrm{cm}^{3}\right)$ & $2.04 E-03$ \\
$c_{\text {porous }}(\mathrm{m} / \mathrm{s})$ & $2.80 E-03$ \\
$p_{\text {crush }}(\mathrm{MPa})$ & $8.00 E+00$ \\
$p_{\text {lock }}(\mathrm{MPa})$ & $6.00 E+03$ \\
Compaction exponent & $3.00 E+00$ \\
$A 1(\mathrm{MPa})$ & $3.53 E+00$ \\
Strength & \\
$G(\mathrm{MPa})$ & $1.25 E+04$ \\
$f_{c}(\mathrm{MPa})$ & $2.30 E+01$ \\
$f_{t} / f_{c}$ & $1.00 E-01$ \\
$f_{s} / f_{c}$ & $1.80 E-01$ \\
$A$ & 1.6 \\
$N$ & $6.10 E-01$ \\
Failure & \\
$D 1$ & $4.00 E-02$ \\
$D 2$ & 1 \\
EFMIN & $1.00 E-02$ \\
Erosion & \\
Geometric strain & 2 \\
\hline
\end{tabular}

cracking. Actually, none of the most commonly used concrete model (K\&C, RHT, HJC, CSCM, or the BF1 Geo Material) can predict the impact cratering or cracking with a high degree of accuracy [22], as the formation process of the crater region is complicated and may be influenced by the strain-rate dependence, compression strength, and tensile strength as well as by crack softening. However, it should be noted that the standard RHT model can gives a closer approximation of the depth of penetration and crater size D than other models. As discussed in [24], node-velocity vectors can be used to estimate crater size by assuming that crater presumably reaches the area at which the nodes do not move out of the concrete target. Thus, the crater region can be shown as in Figure 6(a). The size of the crater region is not accurate enough, so it is necessary to investigate the entrance effect of the crater region by establishing a target with a predrilled hole.

4.1.2. Factors Influencing Penetration Resistance. This section presents the simulation results of projectiles with different nose shapes upon impacting 23 and $35 \mathrm{MPa}$ concrete targets to highlight the factors that influence penetration resistance further. Figure 6(a) depicts the deceleration process of projectiles with different nose shapes upon impacting $23 \mathrm{MPa}$ concrete targets at $400 \mathrm{~m} / \mathrm{s}$. In the simulations, all projectile diameters are almost similar. The $3 \mathrm{CRH}$ and $6 \mathrm{CRH}$ projectiles are similar in length; the same is true for the projectiles with spherical and flat noses. Therefore, the decelerations of projectiles are determined by nose shape. In fact, the sharpest nose resulted in the minimum retarding stress. The deceleration of a flat-nosed projectile almost never reaches a constant value at the end of the penetration process.

Figure 6(b) exhibits the deceleration process of 3CRH projectiles that penetrate 23 and $35 \mathrm{MPa}$ concrete targets at
$400 \mathrm{~m} / \mathrm{s}$. The $35 \mathrm{MPa}$ concrete target exerts considerably greater retarding stress than the $23 \mathrm{MPa}$ concrete target does, thus indicating that decelerations of the projectiles are significantly influenced by the strength of the concrete targets. Actually, the resisting stress increases obviously with the increase in target strength. Therefore, the numerical results suggest that the resisting stress exerted by a given target on the projectile depends only on the strength of the target and on the nose shape of the projectile, since the impact velocity makes little difference at the low velocity range. These analyses have enhanced the validity of the empirical formula.

4.1.3. Penetration of Targets with Holes. As discussed previously, the penetration cavity for the semi-infinite concrete target consists of two parts: the crater and the tunnel regions. The formation process of the crater region is called the entrance phase. In Figure 2, acceleration increases rapidly once the projectile impacts the target surface before reaching a stable phase. Furthermore, the entrance phase is short at high impact velocity. To further highlight the strong effect of the entrance phase on the penetration process, another set of simulations are conducted on concrete targets with a predrilled cylindrical hole around the symmetry axis, as depicted in Figure 1(c). This hole can prevent the target surfaces from moving as a result of the projectile within. The holes have a diameter of $80 \mathrm{~mm}$, which is only slightly larger than the projectile diameter, and a depth of $H=532 \mathrm{~mm}$, which is identical to the length of the projectile and is deep enough to offset the effect of the free impact surface by moving the impact area deep into the target. Hence, the entrance phase hardly affects penetration.

In this section, three groups of simulations are performed with different initial impact velocities: 200, 336.6, and $378.6 \mathrm{~m} / \mathrm{s}$. Figure 5(c) displays the final damage patterns of the target impacted by the projectile at $337.6 \mathrm{~m} / \mathrm{s}$. No obvious crater region is observed in the final damage patterns; thus, the entrance effect has been neutralised by the predrilled hole. Figure 3(b) also highlights the results of these simulations at various impact velocities. The velocitytime curves of targets with holes are more parallel with one another than the curves of regular targets are. Furthermore, Figure $7(\mathrm{a})-7(\mathrm{c})$ shows the deceleration histories of the projectiles in the simulations together with the results of the regular targets. Assuming that no entrance effect is observed in the simulations, the penetration depth $P_{h c}$ of a target with a hole can be calculated with Equation (6) as follows:

$$
P_{h c}=\frac{2 \mathrm{~m}}{\pi d^{2} \rho N} \ln \left(1+\frac{N \rho V_{s}^{2}}{R}\right) .
$$

Table 4 demonstrates the values of $P_{h c}$ together with simulation results $P_{h s}$.

As expected, the penetration depths of $0.405,0.810$, and $0.960 \mathrm{~m}$ were lower than those of regular targets by approximately $14.4 \%, 15.4 \%$, and $16.5 \%$ at velocities of 220.0 , 336.6 , and $378.6 \mathrm{~m} / \mathrm{s}$, respectively. The deceleration histories reach a stable phase more quickly (shortly after impact) 


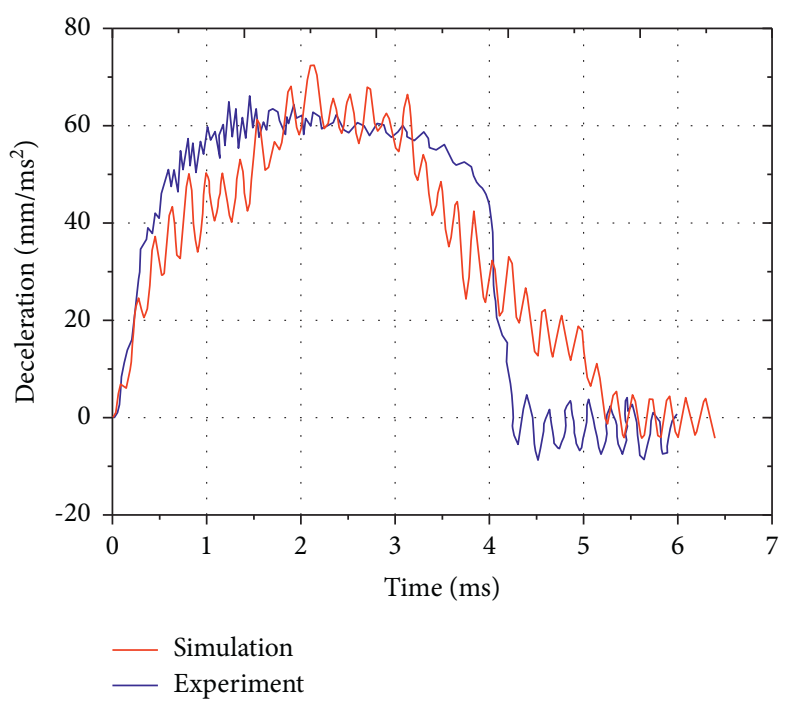

(a)

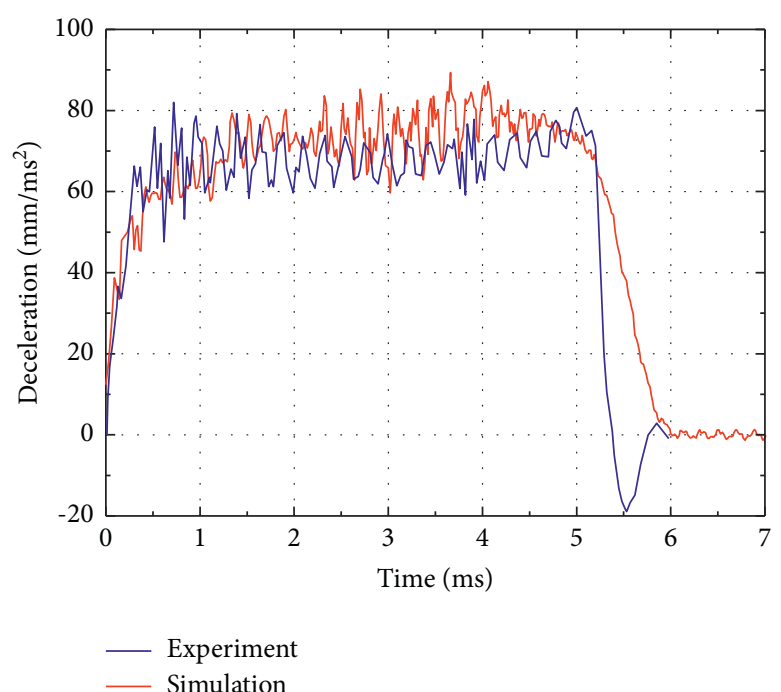

(b)

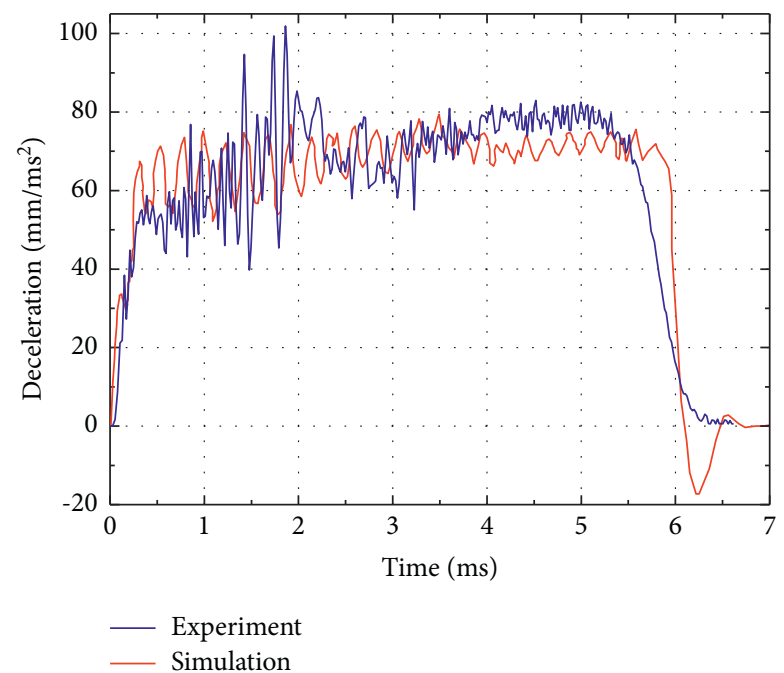

(c)

Figure 2: Deceleration-time curves of experimental data, model prediction, and simulation results: (a) vs $=200.0 \mathrm{~m} / \mathrm{s}$, (b) vs $=336.6 \mathrm{~m} / \mathrm{s}$, and (c) $\mathrm{vs}=378.6 \mathrm{~m} / \mathrm{s}$.

TABLe 3: Experimental $(P)$, theoretical $\left(P_{c}\right)$, and simulated $\left(P_{s}\right)$ penetration depths.

\begin{tabular}{lcccc}
\hline Shot number & Vs $(\mathrm{m} / \mathrm{s})$ & $P(\mathrm{~m})$ & $P_{c}(\mathrm{~m})$ & $P_{s}(\mathrm{~m})$ \\
\hline SNL-00-03 & 200 & 0.42 & 0.416 & 0.473 \\
SNL-00-05 & 336.6 & 0.93 & 0.996 & 0.957 \\
SNL-00-04 & 378.6 & 1.18 & 1.219 & 1.150 \\
\hline
\end{tabular}

during the penetration of targets with holes than during the penetration of regular targets. As a result, penetration time is reduced. In addition, the constant deceleration values of targets with holes are higher than those of regular targets. The differences in the deceleration histories also diminish with the increase of impact velocities, which indicates that the entrance effect is dominant during penetration at low velocity, and this effect exerts a weak influence at high impact velocity because the penetration process can reach the tunnel phase quickly.
4.2. Crater Region Depths. Crater region depth may change regularly under the influence of different projectile and target parameters. In this work, five sets of simulations were performed to highlight crater region depth. These simulations are conducted with different hole depths in concrete targets, target strengths, and projectile nose shapes. The analysis focuses on the penetration depths and the deceleration-time histories.

4.2.1. Effect of Projectiles Nose Shapes. The entrance effect of different nose shapes on the crater region is investigated with ogive-nosed $3 \mathrm{CRH}$ and $6 \mathrm{CRH}$ projectiles, as well as with spherical and flat-nosed ones. The properties of the projectiles and the targets follow those listed in Tables 2 and 3, whereas the geometry size of the projectiles adopts that shown in Figure 1(d). The simulations are conducted with four different impact velocities: $V_{s}=200,300,400$, and 


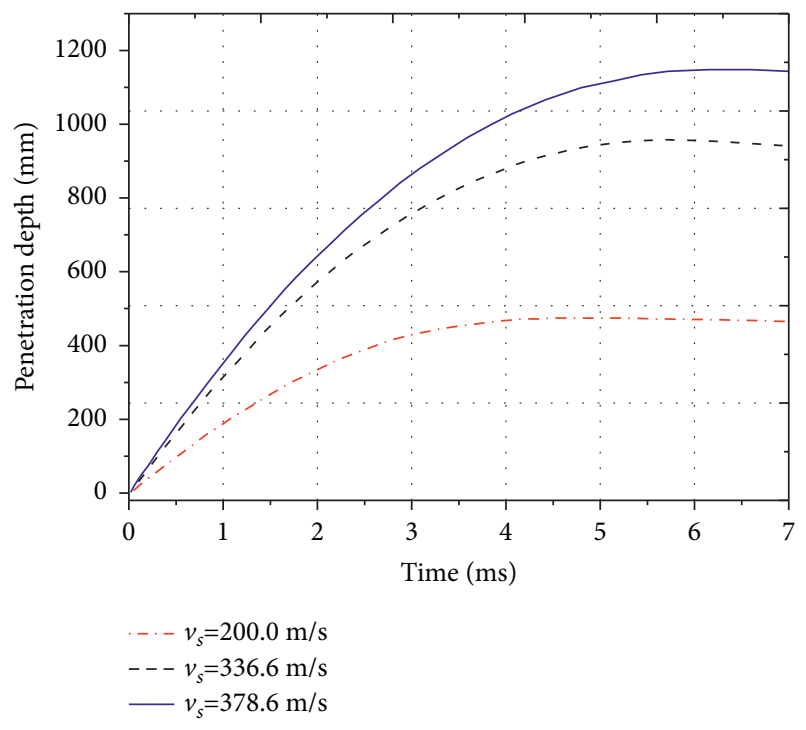

(a)

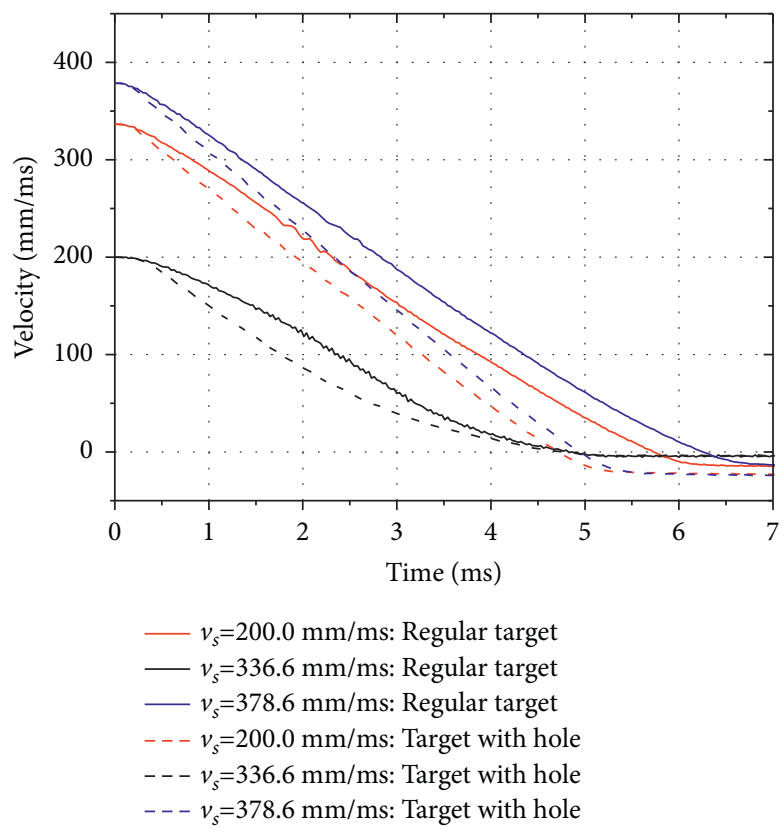

(b)

Figure 3: Penetration histories with different initial velocities (a) penetration depth and (b) velocity.

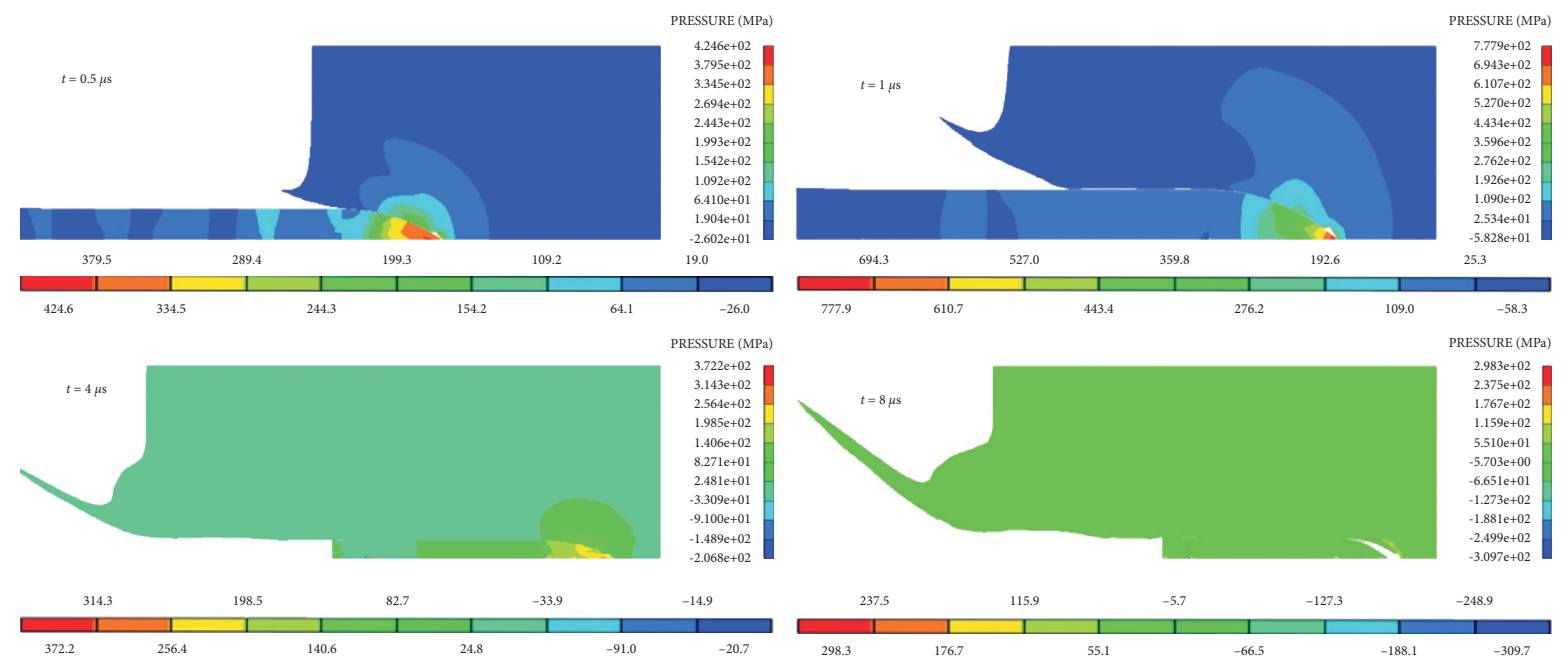

FIGURE 4: Deformation process of the target penetrated by a $3 \mathrm{CRH}$ projectile at $337.6 \mathrm{~m} / \mathrm{s}$.

$500 \mathrm{~m} / \mathrm{s}$. The concrete targets are cylinders with a diameter of $1.83 \mathrm{~m}$ and a length of $1.83 \mathrm{~m}$. However, the target is not long enough for the simulations with $6 \mathrm{CRH}$ projectile. Thus, this set of simulations is performed with a 2.5 -m-long target. Crater depth was previously defined $H=k d$, where $H$ is the hole depth. Figure 8 illustrates the penetration depths for the four types of projectiles at different $k$ values.

As shown in Figure 8, penetration depth for the $3 \mathrm{CRH}$ ogive-nosed projectile is almost constant when $k$ is about 2.4. Figure 9 illustrates the deceleration process of the projectiles of $H=0,2.5 \mathrm{~d}$, and $3.0 \mathrm{~d}$ at $400 \mathrm{~m} / \mathrm{s}$. The two curves of $H=2.5 \mathrm{~d}$ and $3.0 \mathrm{~d}$ almost coincide with each other; hence, a hole depth of $2.5 \mathrm{~d}$ exerts little influence on penetration depth. Figure 5(b) displays the final damage patterns of the target with a $200 \mathrm{~mm}(2.5 \mathrm{~d})$ predrilled hole, which is impacted by the projectile at $337.6 \mathrm{~m} / \mathrm{s}$. No obvious crater region is observed in the final damage patterns, thus suggesting that the front surface has little influence on the penetrating process and that the entrance effect is cancelled out when the depth of the predrilled hole reaches $2.5 d$. A close analysis of the other penetration depth- $k$ curves reveals that penetration depths are constant when $k$ reaches $3.5,1.2$, and 0.8 for the 6CRH ogive-nosed, spherical-nosed, and flatnosed projectiles, respectively. This indicates that the depth of the predrilled hole hardly influences on penetration depth when the depth is deeper than $3.5 \mathrm{~d}, 1.2 \mathrm{~d}$, and $0.8 \mathrm{~d}$. 


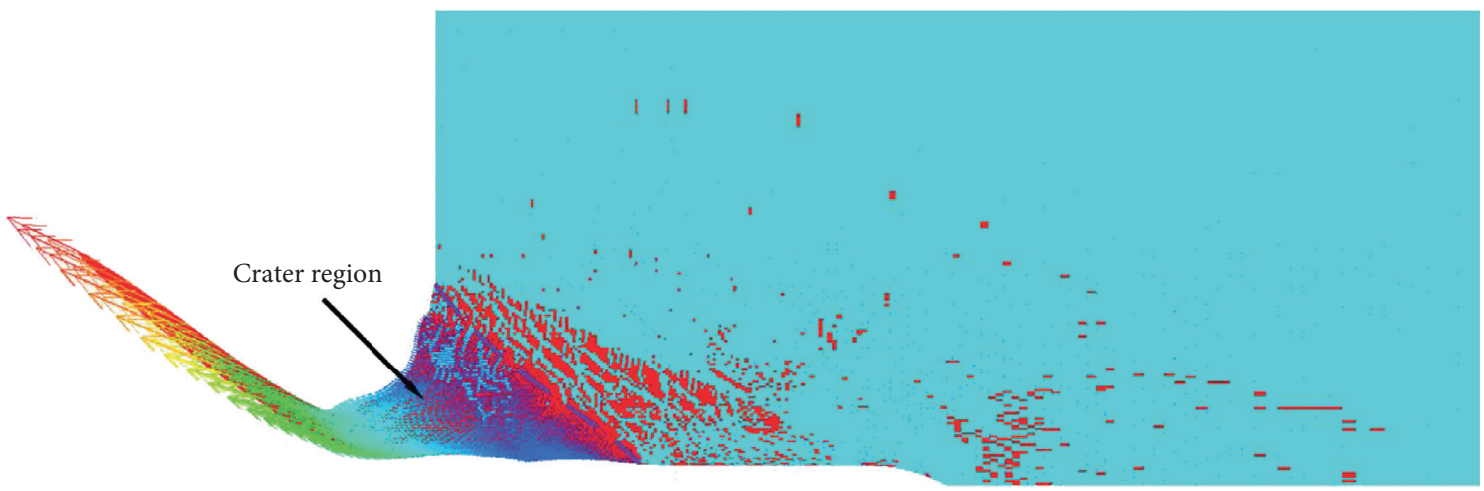

(a)

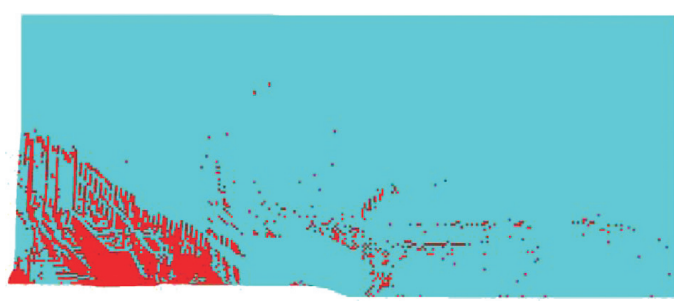

(b)

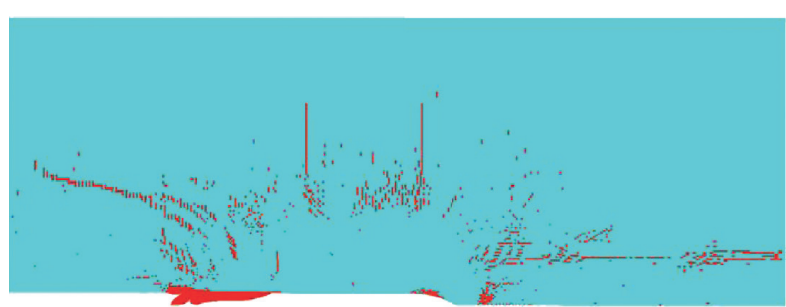

(c)

FiguRe 5: Final damage patterns of the concrete targets: (a) regular target; (b) target with a $200 \mathrm{~mm}$ hole (2.5); (d) hole, and (c) target with a $532 \mathrm{~mm}$ hole.

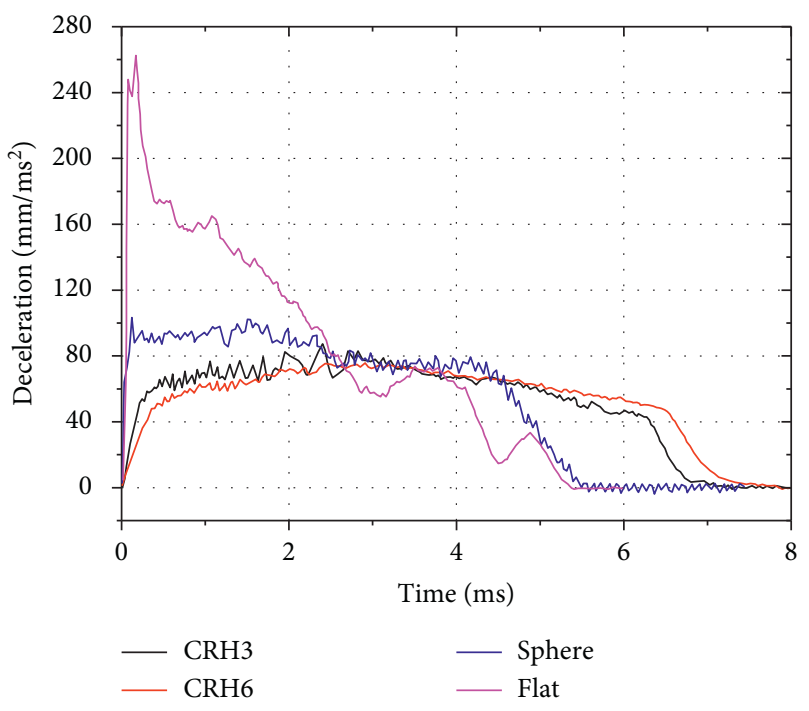

(a)

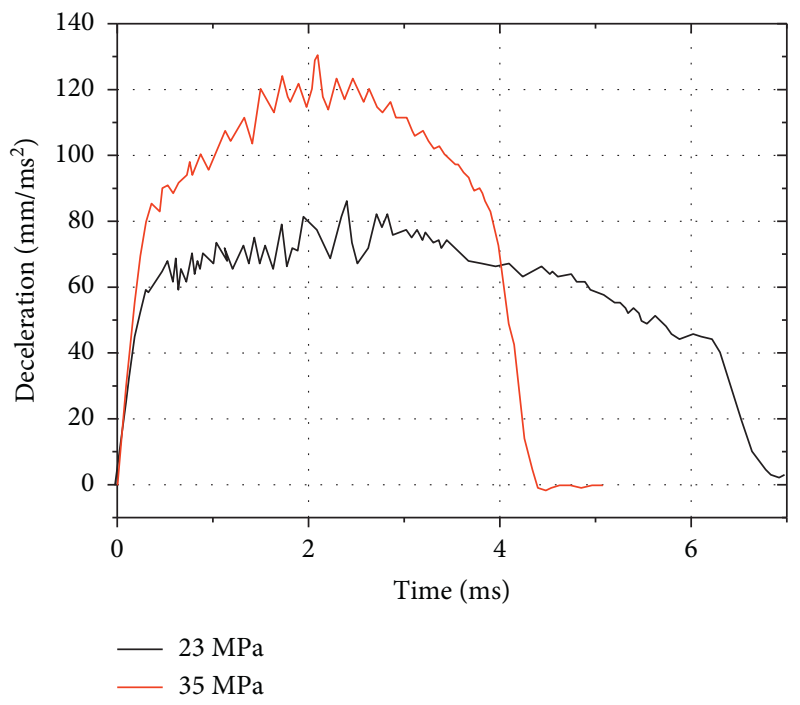

(b)

FIGURE 6: Deceleration process of the projectiles: (a) projectiles with different nose shapes and (b) concrete targets with different strengths.

4.2.2. Effect of Target Strengths. In this section, another set of simulations is conducted with $35 \mathrm{MPa}$ concrete targets to investigate the effect of target strength on crater region depths. The parameters of the $35 \mathrm{MPa}$ concrete material were provided in Standard Material Library of AUTODYN. To make a comparison with the $23 \mathrm{MPa}$ concrete targets, simulations were performed with $3 \mathrm{CRH}$ ogive-nosed projectiles. Figure 10 shows the penetration depths with different $k$ values. When $k$ reaches 2.4 , the penetration depths are almost constant. Figure 11 shows the deceleration process of the projectiles with $H=0,2.4 d$ and $3.0 d$ at $V_{s}=400 \mathrm{~m} / \mathrm{s}$. The deceleration curves obtained for $k=2.4$ and $k=3.0$ almost overlap to each other, which means that the hole depth exerts little influence on penetration depth when the hole is $2.4 d$ deep. This value is close to that of the $23 \mathrm{MPa}$ concrete target $(2.5 d)$ obtained in the previous section. Thus, it can be concluded that the crater region depth is independent of concrete strength. 


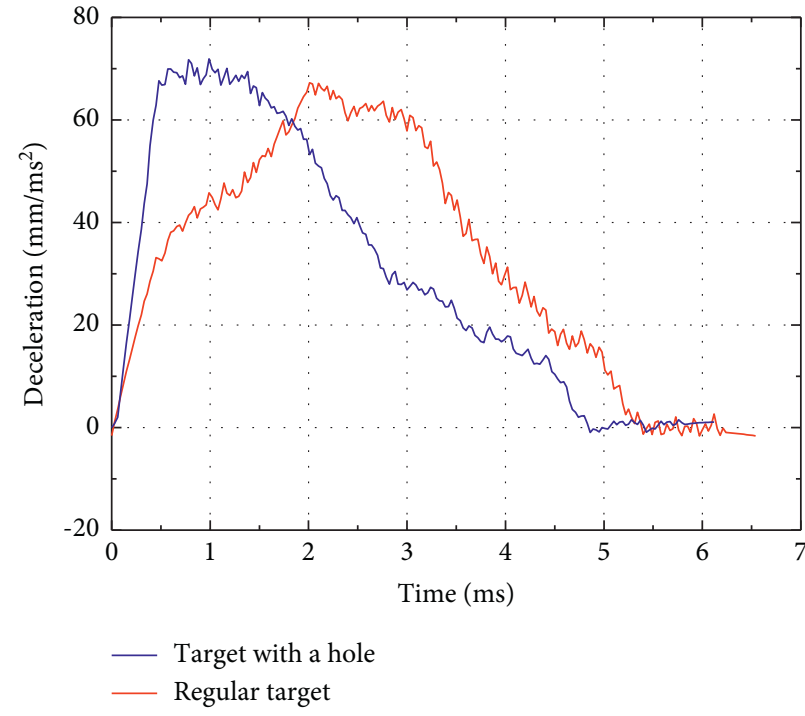

(a)

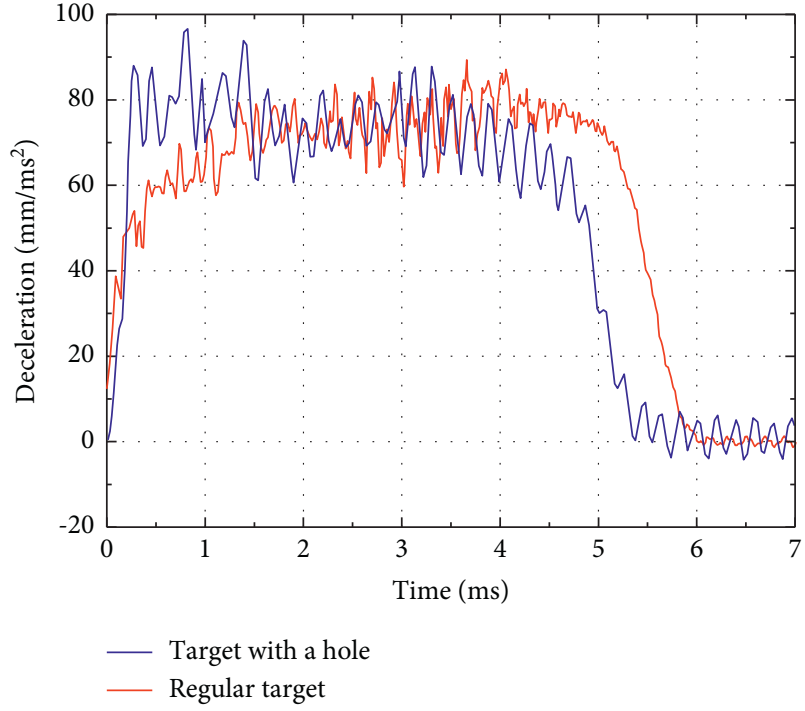

(b)

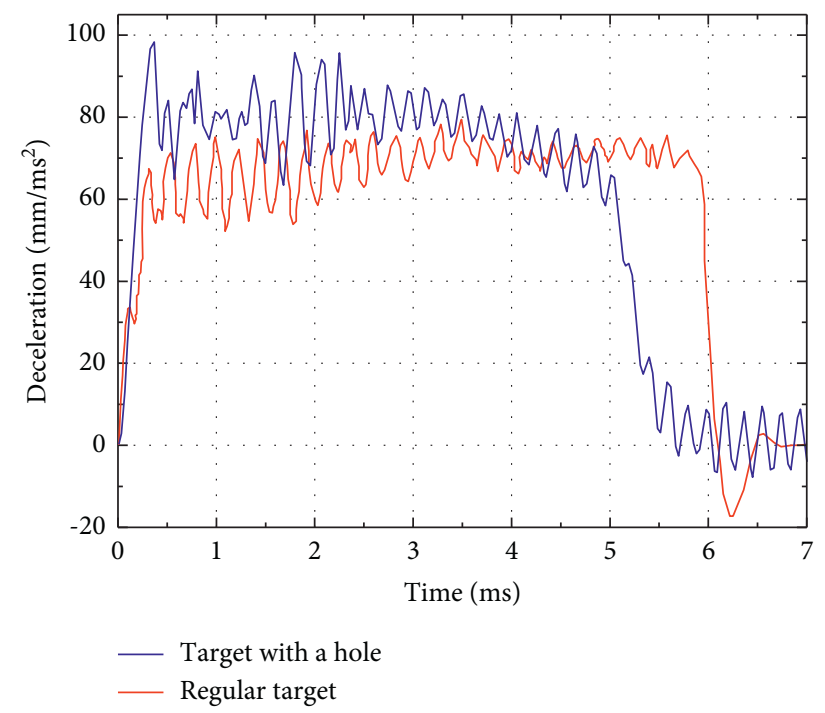

(c)

Figure 7: Deceleration-time curves for the impact on regular targets and targets with predrilled holes: (a) $v_{s}=200.0 \mathrm{~mm} / \mathrm{ms}$, (b) $v_{s}=336.6 \mathrm{~mm} / \mathrm{ms}$, and (c) $v_{s}=378.6 \mathrm{~mm} / \mathrm{ms}$.

TABle 4: Experimental $(P)$, calculated $\left(P_{h c}\right)$, and simulated $\left(P_{s}, P_{h s}\right)$ penetration depths.

\begin{tabular}{lccccc}
\hline Shot number & $V_{s}(\mathrm{~m} / \mathrm{s})$ & $P(\mathrm{~m})$ & $P_{s}(\mathrm{~m})$ & $P_{h c}(\mathrm{~m})$ & $P_{h s}(\mathrm{~m})$ \\
\hline SNL-00-03 & 200.0 & 0.42 & 0.473 & 0.339 & 0.405 \\
SNL-00-05 & 336.6 & 0.93 & 0.957 & 0.917 & 0.810 \\
SNL-00-04 & 378.6 & 1.18 & 1.150 & 1.140 & 0.960 \\
\hline
\end{tabular}

4.2.3. Formula of the Crater Region Depth. The crater depth becomes constant when the entrance effect is counteracted by predrilled holes in concrete targets, while the influence of concrete strength and the impact velocity on crater region depth can be ignored. Thus, the hole depth can be regarded as crater region depth. In the simulations, penetration depth becomes constant when $k$ value reaches 2.5 (2.4), 3.5, 1.2, and 0.8 for $3 \mathrm{CRH}, 6 \mathrm{CRH}$, spherical-nosed, and flat-nosed projectiles, respectively. These values are similar to that obtained through the empirical formula $k=0.707+L_{0} / d$ [11]: $2.365,3.105,1.207,0.707$, where $L_{0}, d$ are projectile nose height and projectile diameter, respectively. In consideration of the accuracy and convenience of the formula, the depth of crater region can be simplified as

$$
k=0.7+\frac{L_{0}}{d}
$$




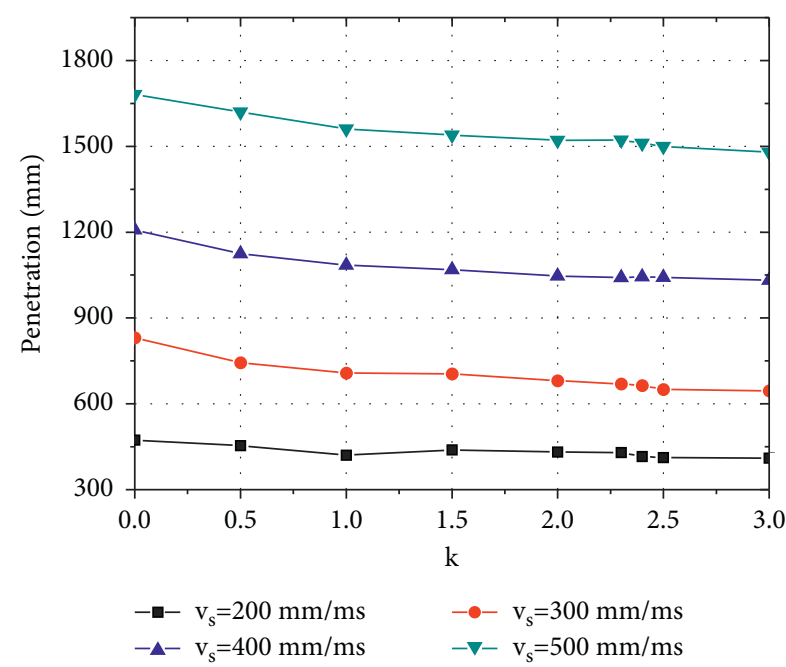

(a)

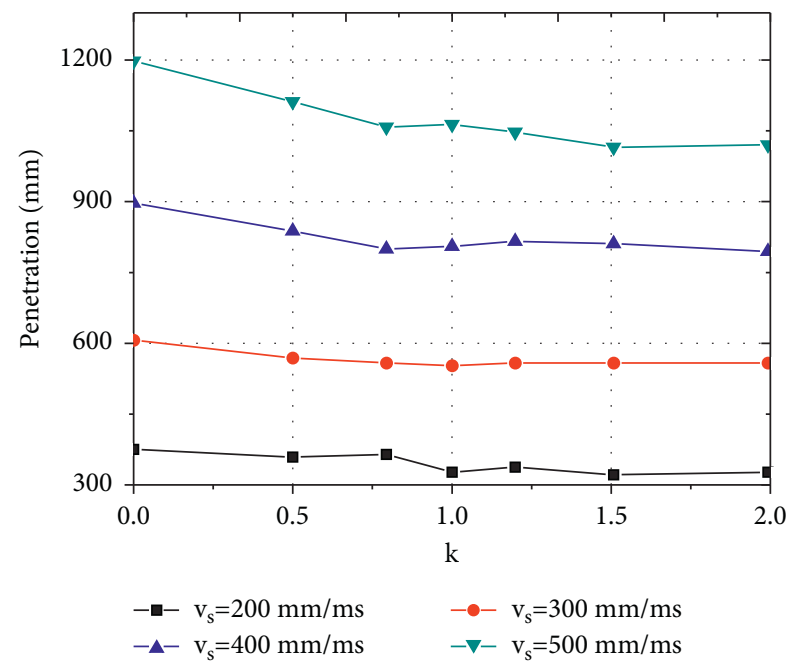

(c)

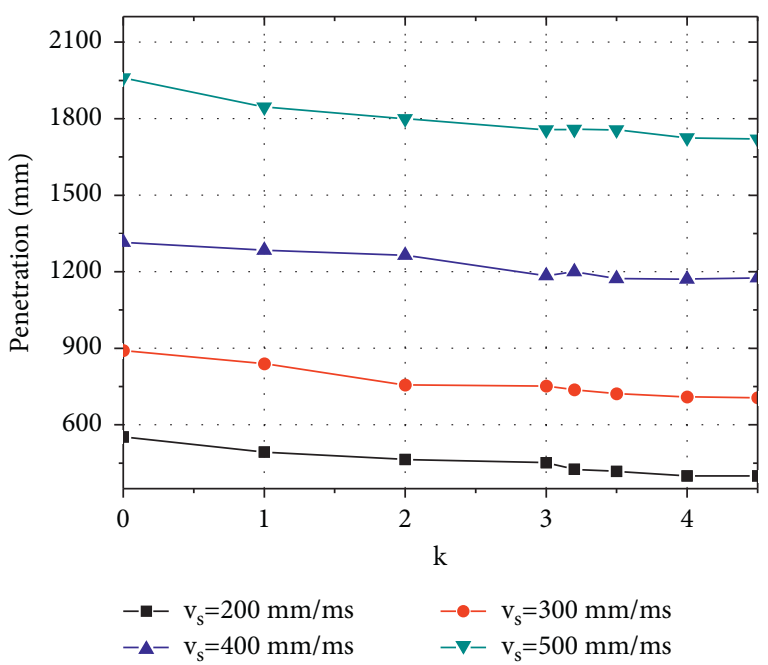

(b)

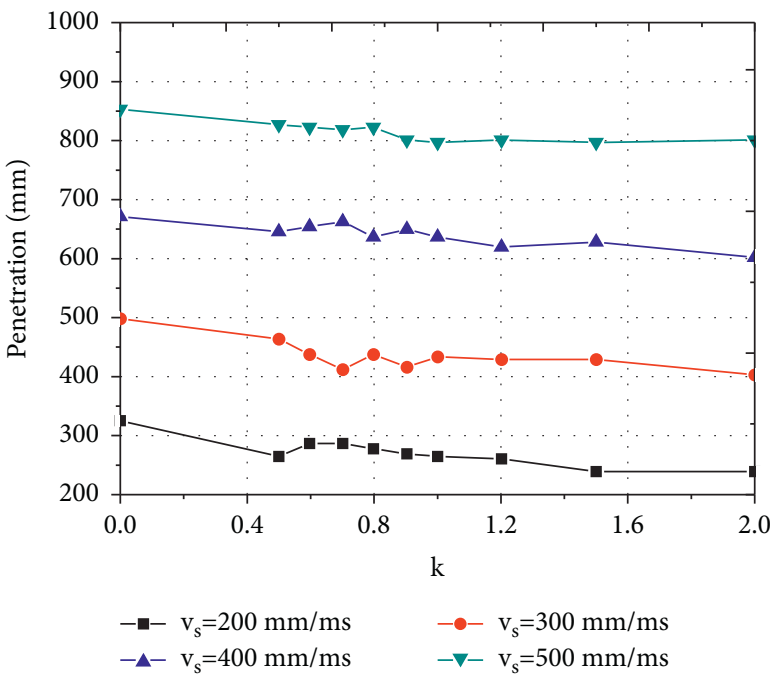

(d)

FIgURE 8: Penetration-(k) curves obtained at different impact velocities: (a) 3CRH projectile, (b) 6CRH projectile, (c) spherical-nosed projectile, and (d) flat-nosed projectile.

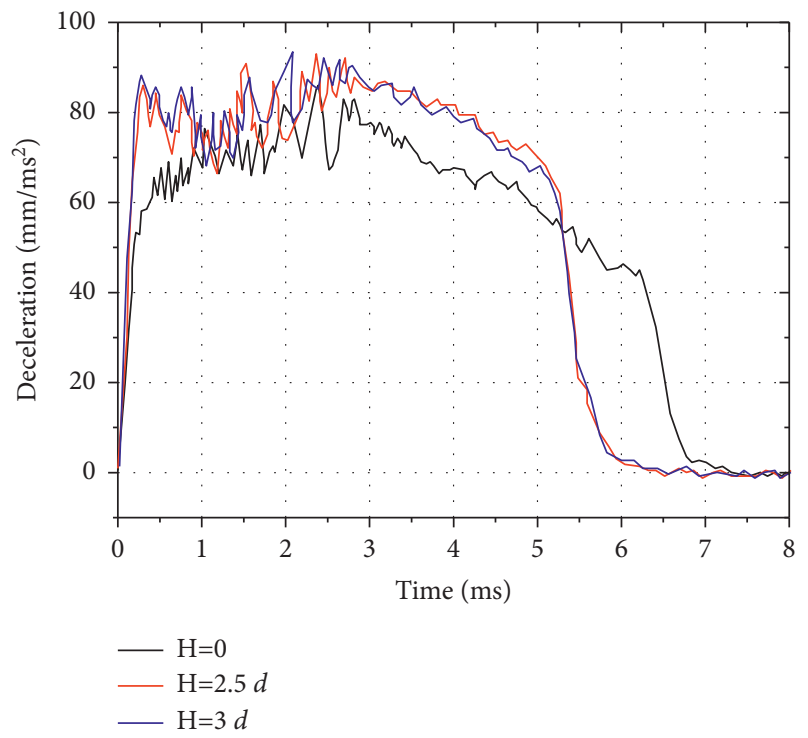

Figure 9: Deceleration-time curves for the $23 \mathrm{MPa}$ targets with different hole depths. 


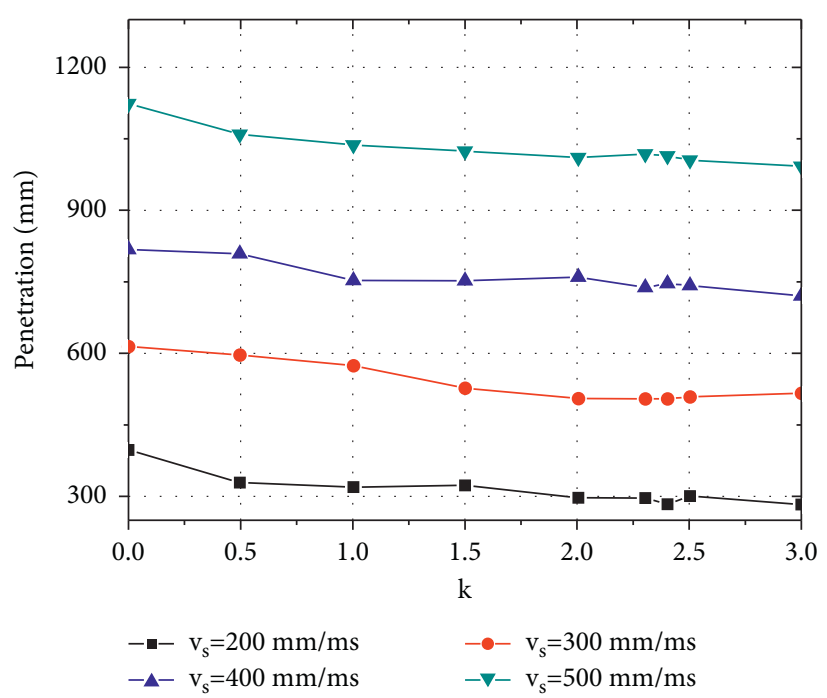

Figure 10: Penetration-k curves for $35 \mathrm{MPa}$ targets at different impact velocities.

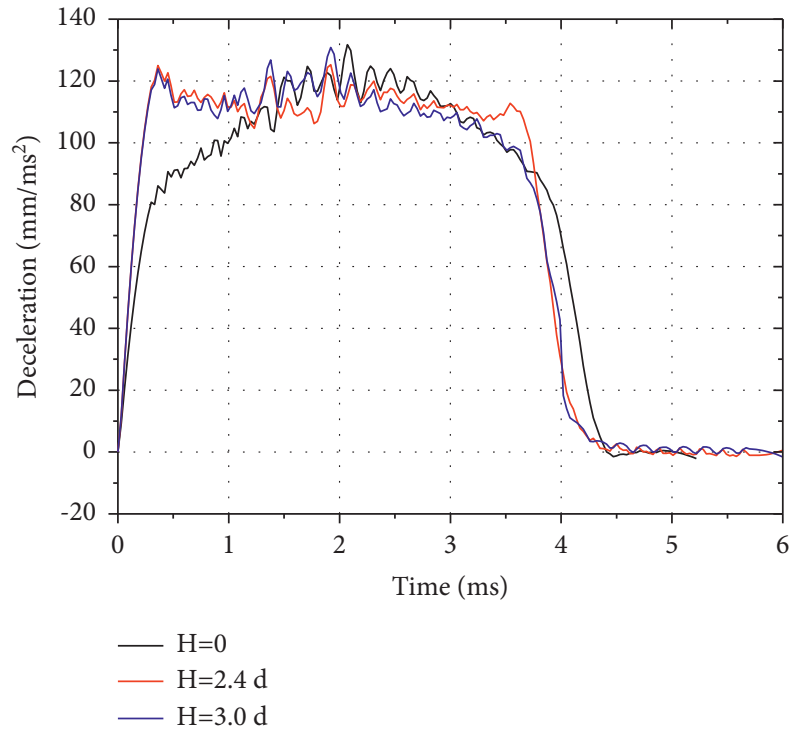

Figure 11: Deceleration-time curves for the $35 \mathrm{MPa}$ targets with different hole depths.

4.3. Modified Formula and Validation. As discussed in Section 4.2.3, $k d$ can more accurately describe the crater region depth than $2 d$. Hence, Forrestal's empirical formula must be modified with Eq. (7), and the new analytical model can be given as

$$
\begin{aligned}
P & =\frac{2 m}{\pi d^{2} \rho N} \ln \left(1+\frac{N \rho V_{1}^{2}}{R}\right)+k d, \quad P>k d, \\
V_{1}{ }^{2} & =\frac{4 m V_{s}^{2}-\pi k d^{3} R}{4 m+\pi k d^{3} N \rho} .
\end{aligned}
$$

Figure 12(a) shows a comparison of the penetration depths obtained with Forrestal's formula and the modified formula. The penetration depths obtained from the modified formula are closer to the experimental data; therefore, the modified Forrestal's formula accurately predicts the penetration depth of concrete targets. The experimental data were also compared with the empirical formulas $[13,14,17,19]$ to highlight the advantages and accuracy of the modified Forrestal's formula in this work, as shown in Figures 12(b)-12(d). The predictions of the modified Forrestal's formula are consistent with the experimental data with different compressive strengths of concrete targets. Since the modified Forrestal's formula has taken the size effect into consideration, it may perform better than others for the concrete targets penetrated by the steel projectiles with a larger diameter. As is shown in Figure $12(\mathrm{c})$, the $39 \mathrm{MPa}$ concrete targets penetrated by the steel projectiles, which has a larger diameter of $76.2 \mathrm{~mm}$, and the prediction of the modified Forrestal's formula shows a higher precision than the other formulas. The deformation of the ogive-nosed projectiles is slight enough to be neglected; thus, penetration depth can be predicted by using the modified formula obtained in this work. As the crater depth will account for larger proportion of 


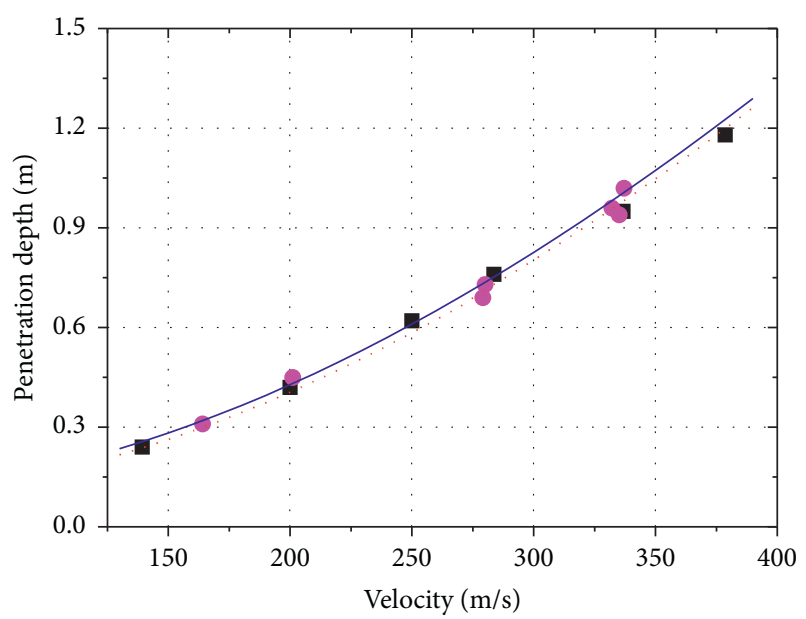

- Experimental data [16] ….. Forrestal's formula

- Experimental data [18] — Modified formula

(a)

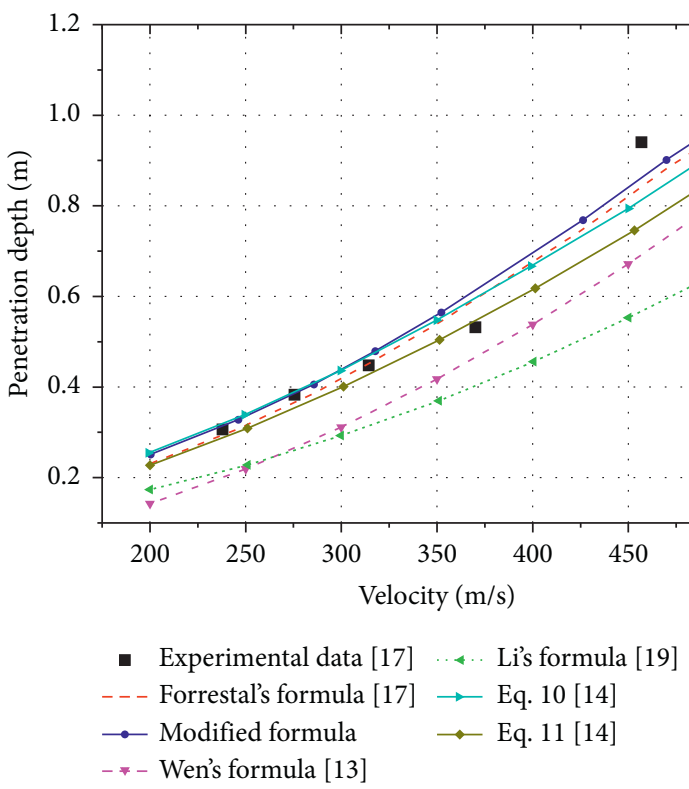

(c)

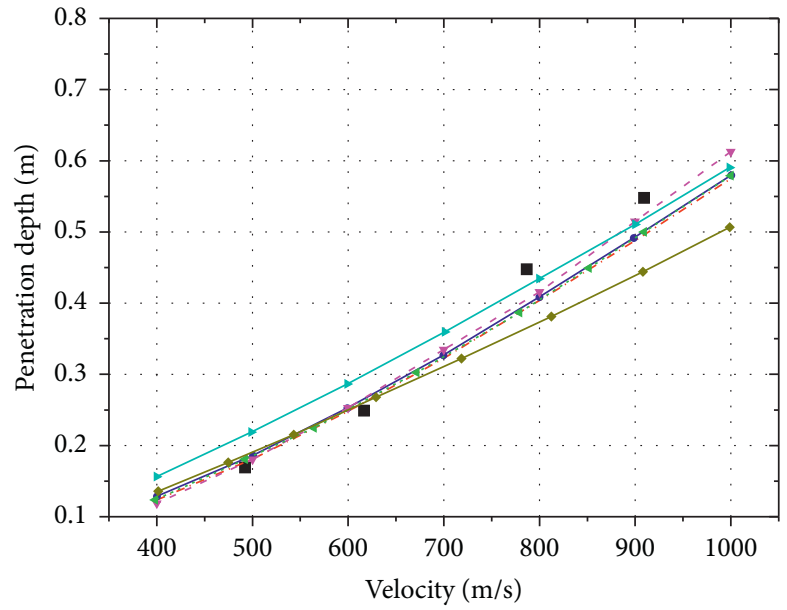

- Experimental data [16] $\rightarrow$ Li's formula [19]

- - - Forrestal's formula [17] $\rightarrow$ Eq. 10 [14]

$\rightarrow$ Modified formula … Eq. 11 [14]

- - Wen's formula [13]

(b)

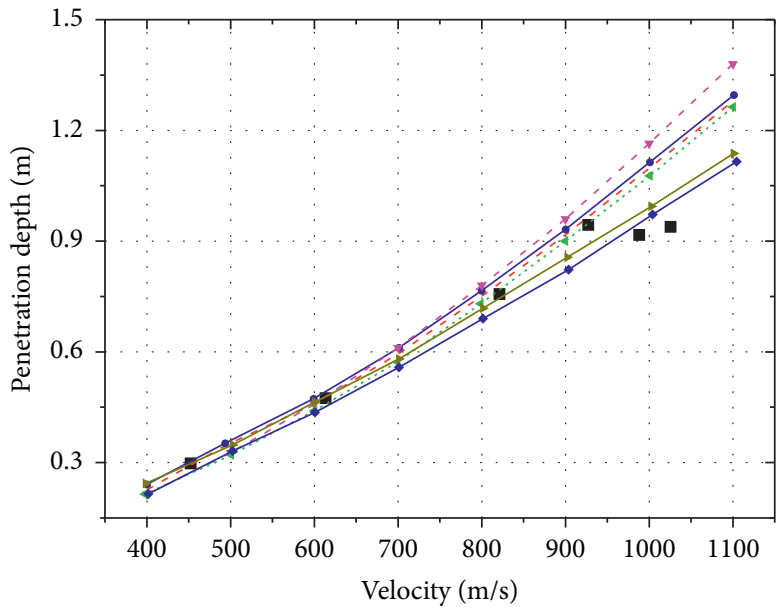

- Experimental data [16] $\ldots 4$... Li's formula [19]

- - - Forrestal [17] $\rightarrow$ Eq. 10 [14]

$\rightarrow$ Modified formula $\rightarrow$ Eq. 11 [14]

$-\%$ - Wen's formula [13]

(d)

Figure 12: Comparison of the different formulas in predicting the penetration depths: (a) $23 \mathrm{MPa}$, (b) $21.6 \mathrm{MPa}$, (c) $39 \mathrm{MPa}$, and (d) $62.8 \mathrm{MPa}$.

penetration depth for the penetration at low velocity, the prediction precision of the modified Forrestal's formula is significantly higher than that of the other formulas.

\section{Conclusion}

In this work, a further investigation on the penetration into concrete targets was conducted to make a more accurate prediction of penetration depths, based on the numerical simulations of entrance effect. Following conclusions were obtained as
(1) In the penetration process, the resisting stress exerted on the projectile is dependent on the shape of the projectile nose, concrete target strength, and impact velocity.

(2) The free surface effect of a regular target reduces the penetration resistance of the projectile in the early stages of penetration. It leads to predrilled targets having a smaller depth of penetration than regular targets at the same penetration velocity, and the decelerations reach the peak and keep stable more quickly. 
(3) The entrance effect also diminishes with increasing impact velocity. Based on the simulation of entrance effect, a modified formula was proposed and validated to predict the crater region depth. Thus, the modified formula can predict the penetration depth for concrete targets penetrated by nondeformable projectiles with a higher accuracy, especially for operating conditions such as low-velocity penetration or armour perforation of target slabs.

\section{Abbreviations \\ SHPB: Split Hopkinson Pressure Bar \\ CRH: Caliber-radius-head \\ RHT: The Riedel-Hiermaier-Thoma model \\ K\&C: Karagozian and Case model \\ RHT: The Riedel-Hiermaier-Thoma model \\ HJC: The Holmquist-Johnson-Cook model \\ CSCM: The Continuous Surface Cap model \\ BF1: The Brannon-Fossum model.}

\section{Data Availability}

The data used to support the results of this study are available from the corresponding authors upon request.

\section{Conflicts of Interest}

The authors declare that they have no conflicts of interest.

\section{Acknowledgments}

This work was supported by the Science and Technology Innovation Project of Higher Education Department of Shanxi Province (Nos. 2019L0493 and 2019L0497) and the Young Foundation of Shanxi University of Finance and Economics (Nos. QN-2019004 and QN-2019004).

\section{References}

[1] Z. U. Rehman and G. Zhang, "Shear coupling effect of monotonic and cyclic behavior of the interface between steel and gravel," Canadian Geotechnical Journal, vol. 56, no. 6, pp. 876-884, 2019.

[2] Z. Zhou, W. Ma, S. Zhang, Y. Mu, and G. Li, "Effect of freezethaw cycles in mechanical behaviors of frozen loess," Cold Regions Science and Technology, vol. 146, pp. 9-18, 2018.

[3] Z. U. Rehman and G. Zhang, "Three-dimensional elastoplastic damage model for gravelly soil-structure interface considering the shear coupling effect," Computers and Geotechnics, vol. 129, p. 103868, 2021.

[4] H. W. Yang, X. C. Jin, and J. Zhang, "Analysis on Mass loss of different sized projectiles penetrating into concrete targets[J]," International Journal of Mechanical Sciences, p. 131, 2017.

[5] Z. U. Rehman, F. Luo, T. Wang, and G. Zhang, "Large-scale test study on the three-dimensional behavior of the gravel-concrete interface of a CFR dam," International Journal of Geomechanics, vol. 26, no. 6, 2020.

[6] P. Zhang, X. Li, Z. Wang, L. Zhao, and X. Yan, "Dynamic blast loading response of sandwich beam with origami-inspired core," Results in Physics, vol. 10, pp. 946-955, 2018.
[7] Z. U. Rehman and G. Zhang, "Cyclic behavior of gravel-steel interface under varying rotational shear paths," Canadian Geotechnical Journal, vol. 58, no. 3, pp. 305-316, 2021.

[8] L. Jing, Z. H. Wang, Z. Wang, and L. Zhao, "The dynamic response of sandwich panels with cellular metal cores to localized impulsive loading," Composites Part B: Engineering, vol. 94, pp. 52-63, 2016.

[9] A. A. Konyaev, V. F. Tolkachev, and T. M. Platova, "Experimental testing of the fracture of concrete and reinforced concrete plates under impact," Journal of Applied Mechanics and Technical Physics, vol. 56, no. 6, pp. 1031-1037, 2015.

[10] N. N. Belov, N. T. Yugov, D. G. Kopanitsa, and A. A. Yugov, "Stress analysis of concrete and reinforced-concrete slab structures under a high-velocity impact," Journal of Applied Mechanics and Technical Physics, vol. 46, no. 3, pp. 444-451, 2005.

[11] Q. M. Li, S. R. Reid, H. M. Wen, and A. R. Telford, "Local impact effects of hard missiles on concrete targets," International Journal of Impact Engineering, vol. 32, no. 1-4, pp. 224-284, 2005.

[12] R. Ranjan, S. Banerjee, R. K. Singh, and P. Banerji, "Local impact effects on concrete target due to missile: an empirical and numerical approach," Annals of Nuclear Energy, vol. 68, pp. 262-275, 2014.

[13] H. M. Wen and Y. Yang, "A note on the deep penetration of projectiles into concrete," International Journal of Impact Engineering, vol. 66, pp. 1-4, 2014.

[14] Y. Peng, Q. Fang, H. Wu, Z. M. Gong, and X. Z. Kong, "Discussion on the resistance forcing function of projectiles penetrating into concrete targets," Engineering Mechanics, vol. 32, pp. 112-119, 2015.

[15] R. F. Bishop, R. Hill, and N. F. Mott, "The theory of indentation and hardness test," Proceedings of the Physical Society, vol. 57, pp. 147-159, 1954.

[16] M. J. Forrestal, D. J. Frew, S. J. Hanchak, and N. S. Brar, "Penetration of grout and concrete targets with ogive-nose steel projectiles," International Journal of Impact Engineering, vol. 18 , no. 5, pp. 465-476, 1996.

[17] M. J. Forrestal, D. J. Frew, J. P. Hickerson, and T. A. Rohwer, "Penetration of concrete targets with deceleration-time measurements," International Journal of Impact Engineering, vol. 28, no. 5, pp. 479-497, 2003.

[18] D. J. Frew, M. J. Forrestal, and J. D. Cargile, "The effect of concrete target diameter on projectile deceleration and penetration depth," International Journal of Impact Engineering, vol. 32, no. 10, pp. 1584-1594, 2006.

[19] Q. M. Li and X. W. Chen, "Dimensionless formulae for penetration depth of concrete target impacted by a non-deformable projectile," International Journal of Impact Engineering, vol. 28, no. 1, pp. 93-116, 2003.

[20] Century Dynamics Ltd, AUTODYN Theory Manual, version 6.1, Century Dynamics Ltd, Horsham, UK, 2005.

[21] C. Y. Tham, "Reinforced concrete perforation and penetration simulation using AUTODYN-3D," Finite Elements in Analysis and Design, vol. 41, no. 14, pp. 1401-1410, 2005.

[22] R. Brannon and S. Leelavanichkul, Survey of Four Damage Models for Concrete, Sandia National Laboratories, Albuquerque, NM, USA, 2009.

[23] Z. Zhou, W. Ma, S. Zhang, C. Cai, Y. Mu, and G. Li, "Damage evolution and recrystallization enhancement of frozen loess," International Journal of Damage Mechanics, vol. 27, no. 8, pp. 1131-1155, 2018.

[24] U. N. K. Gylltof, "Comparative numerical studies of projectile impacts on plain and steel-fiber reinforced concrete," International Journal of Impact Engineering, vol. 38, pp. 95-105, 2011. 